\title{
Synergistic induction of the Fas (CD95) ligand promoter by Max and NFKB in human non-small lung cancer cells
}

\author{
Zoltan Wiener, ${ }^{\text {a,b,1 }}$ Edgar C. Ontsouka, ${ }^{\text {a,1,2 }}$ Sabine Jakob, ${ }^{\text {a }}$ Ralph Torgler,, 3 \\ Andras Falus, ${ }^{\mathrm{b}, \mathrm{c}}$ Christoph Mueller, ${ }^{\mathrm{a}}$ and Thomas Brunner ${ }^{\mathrm{a}, *}$ \\ a Division of Immunopathology, Institute of Pathology, University of Berne, Berne, Switzerland \\ ${ }^{\mathrm{b}}$ Department of Genetics, Cell and Immunobiology, Semmelweis University, Hungarian Academy of Sciences, Budapest, Hungary \\ ${ }^{\mathrm{c}}$ Molecular Immunology Research Group, Hungarian Academy of Sciences, Budapest, Hungary
}

\begin{abstract}
Fas (CD95/APO-1) ligand is a member of the Tumor Necrosis Factor family and a potent inducer of apoptosis. Fas ligand is expressed in activated $\mathrm{T}$ cells and represents a major cytotoxic effector mechanism by which T cells kill their target cells. Activation-induced Fas ligand expression in T cells is under the stringent control of various transcription factors, including nuclear factor $\kappa \mathrm{B}(\mathrm{NF} \kappa \mathrm{B})$ and c-Myc/Max. There is accumulating evidence that Fas ligand is also expressed by various non-hematopoietic tumor cells, however, little is known about Fas ligand regulation in tumor cells. In this study, we have analyzed the regulation of the Fas ligand gene promoter induction in two non-small cell lung cancer cell lines, with a major focus on the role of the c-Myc/Max transcription factor. Our results revealed that inhibition of c-Myc/ Max did not substantially reduce basal levels of Fas ligand promoter activity, nor did overexpression of c-Myc significantly induce promoter activity. In contrast, we observed that overexpression of Max resulted in a marked increase in basal promoter activity and synergistically enhanced phorbolester- and doxorubicin-induced NFkB-mediated Fas ligand promoter activity. These results were confirmed by analyzing endogenous Fas ligand transcription. We conclude that high levels of Max and stress-induced NFkB activation may result in elevated expression of Fas ligand in human lung cancer cells and possibly contribute to Fas ligand-associated immune escape mechanisms.
\end{abstract}

Keywords: Apoptosis; Transcription; Signaling; Tumor necrosis factor family; Tumor cells

\section{Introduction}

c-Myc is a proto-oncogene, which is crucially involved in the proliferation and the development of different tumors. c-Myc expression is often deregulated in tumor cells due to overexpression or gene amplification. Together with its heterodimerization partner Max, c-Myc forms a transcription factor complex and mediates its tumor-promoting

* Corresponding author. Division of Immunopathology, Institute of Pathology, University of Berne, Murtenstrasse 31, PO Box 62, 3010 Berne, Switzerland. Fax: +41-31-381-87-64.

E-mail address: tbrunner@pathology.unibe.ch (T. Brunner).

${ }^{1}$ These authors contributed equally to this study and therefore share first-authorship.

${ }^{2}$ Current address: Division of Animal Nutrition and Physiology, Institute of Animal Genetics, Nutrition and Housing, Faculty of Veterinary Medicine, University of Berne, Bremgartenstr 109a, 3012 Berne, Switzerland.

${ }^{3}$ Current address: Institute of Biochemistry, University of Lausanne, Chemin des Boveresses 155, 1066 Epalinges, Switzerland. properties through the induction of growth control genes (reviewed in Refs. [1-4]). c-Myc is essential for cell cycle progression, not only in tumor cells, but also in untransformed cells, and disruption of the c-Myc gene in mice results in embryonic lethality [5].

However, c-Myc not only causes cell growth and proliferation, but inappropriate expression of c-Myc may also induce apoptosis. For example, inducible activation of c$\mathrm{Myc}$ in fibroblast mediates proliferation, whereas overexpression of c-Myc in serum-starved fibroblasts causes rapid apoptosis [6]. This observation is also made in tumor cells in vivo, where overexpression of c-Myc results in an initial phase of proliferation followed by massive apoptosis, and only the combined overexpression of c-Myc with the antiapoptotic molecule Bcl-xL can rescue cells from apoptosis and supports tumor formation [7].

Recently, the mechanism of c-Myc-induced apoptosis in fibroblasts has been investigated and found to be dependent 
on the expression of the apoptosis-inducing receptor Fas (APO-1/CD95) and its ligand [8]. Similarly, we have recently described that antigen receptor-induced Fas ligand expression in $\mathrm{T}$ cells is dependent on the activity of the cMyc/Max transcription factor, since inhibition of c-Myc by antisense oligonucleotides [9], pharmacological drugs $[10,11]$ or overexpression of dominant-negative inhibitors [9] resulted in a profound inhibition of FasL expression. cMyc/Max appears to mediate its FasL-inducing activity through direct interaction with a noncanonical binding site within the FasL promoter [12]. Thus, the expression of FasL appears to be linked to cell cycle control genes, such as cMyc and Max.

FasL is not only expressed by activated T cells, but also by various tumors of hematopoietic and non-hematopoietic origin (reviewed in Ref. [13]). Similarly, we have found that human lung cancer isolates and cell lines express various levels of functional FasL [14]. Although the precise role of tumor-expressed FasL is still not fully understood, it has been suggested that tumor-expressed FasL may support immune escape by inducing apoptosis in Fas-expressing tumor-infiltrating leukocytes (reviewed in Refs. $[13,15,16]$ ). In agreement with this notion, we have observed that in a mouse model for mammary gland tumors, FasL-expressing tumors are persisting whereas FasL-negative tumors are eliminated by the immune system [17].

Little is currently known about the regulation of FasL in non-hematopoietic tumor cells. In particular, many of the signal transduction pathways and transcription factors that regulate the FasL promoter are also activated in tumor cells and may possibly drive FasL transcription. Deregulated cMyc expression is frequently observed in tumor cells and supports the excessive growth of these cells (reviewed in Ref. [3]). In particular, many lung cancer cells show c-Myc gene amplification and/or overexpression [18-20]. We thus aimed at investigating the role of c-Myc in basal and stress-induced FasL expression in the two non-small cell lung cancer (NSCLC) lines H2009 and Calu-6. Our results reveal that Max, rather than c-Myc overexpression leads to a synergistic induction of the FasL promoter together with NFkB-activating signals. We conclude that high levels of Max may enhance stress-induced FasL expression in lung cancer cells.

\section{Material and methods}

\section{Cells and reagents}

The human non-small cell lung cancer cell lines H2009 [14] and Calu-6 were obtained from ATCC (Manassas, VA) and maintained in Iscove's modified Dulbecco's medium (IMDM), containing 5\% FCS, 2 mM L-glutamine, $100 \mathrm{U} / \mathrm{ml}$ penicillin, $100 \mu \mathrm{g} / \mathrm{ml}$ streptomycin (complete medium). Phorbol-myristate-acetate (PMA) was purchased from Sigma (St. Louis, MO), doxorubicin, and lactacystin from Calbiochem (Juro, Lucerne, Switzerland).

\section{FasL promoter reporter assay}

FasL promoter activity was assessed as previously described $[9,12,21]$. Briefly, H2009 and Calu-6 were harvested by trypsinization and seeded into 6 -well plates at $3-4 \times 10^{5}$ cells/well. After $24 \mathrm{~h}$, cells were transiently transfected with $0.15 \mu \mathrm{g}$ luciferase reporter construct, containing a $1.2-\mathrm{kb}$ fragment of the human FasL promoter (HFLP) [21], and $0.08 \mu \mathrm{g}$ of pCMV $\beta$ Gal (BD Biosciences Clontech, Palo Alto, CA) in complete medium using Effectene transfection reagents (Qiagen, Basel, Switzerland). After overnight culture cells were washed in PBS and further cultured in complete medium, cells were then stimulated for $16 \mathrm{~h}$ with medium control, or increasing concentrations of PMA or doxorubicin, washed, harvested, and lysed in $100 \mu$ lysis buffer $\left(0.2 \%\right.$ Triton X-100, $92 \mathrm{mM} \mathrm{KH_{2 }} \mathrm{PO}_{4}, 0.91 \mathrm{mM}$ $\mathrm{KH}_{2} \mathrm{PO}_{4}, 1 \mathrm{mM}$ DTT). Luciferase activity in the cell-free supernatant was assessed in a TD-20/20 Luminometer (BioSystems, Sunnyvale, CA), and normalized with $\beta$ galactosidase activity to correct for different transfection efficiencies. In some experiments, cells were also co-transfected with expression plasmids containing human c-Myc, Max (kindly provided by R. Eisenman, Fred Hutchinson Cancer Research Center, Seattle, WA) [9,12], the dominantnegative Max mutant MaxRX (kindly provided by B. Amati, DNAX Research Institute, Palo Alto, CA) [9], the MAP kinase kinase kinase MEKK1 or the NFKB subunit RelA p65 [21-23]. The different DNA concentrations in the different transfections were corrected with the empty vector.

\section{Detection of FasL transcription by RT-PCR}

MH2009 cells were either transfected with control vector, Max, or hFasL as positive control, and then stimulated with buffer control or PMA. After $10 \mathrm{~h}$, cells were harvested and total RNA was isolated. Two micrograms RNA were reverse transcribed using a commercial kit and manufacturer's suggested conditions (Promega, Madison, WI). For realtime PCR $1 \mu \mathrm{l}$ of 1:2 diluted RT product was then added to the PCR mix consisting of $12.5 \mu \mathrm{l}$ SYBR Green/Taq polymerase master mix (Applied Biosystems, Foster City, CA), $1.5 \mu$ l forward primer $(300 \mathrm{nM}), 1.5 \mu \mathrm{l}$ reverse primer (300 nM) and $8.5 \mu 1 \mathrm{H}_{2} \mathrm{O}$. The following primers were used: hFasL forward $5^{\prime}$-AGC TGG CAG AAC TCC GAG AGT$3^{\prime}$, reverse $5^{\prime}$-CCA CCC TTC TTA TAC TTC ACT CCA GAA-3'; GAPDH forward 5' -TTC ACC ACC ATG GAG AAG GC-3' ; reverse $5^{\prime}$-GC ATG GAC TGT GGT CAT GA $3^{\prime}$. The DNA was amplified in a TaqMan PCR machine (Applied Biosystems) using the following conditions: $2 \mathrm{~min}$ $50^{\circ} \mathrm{C}, 10 \mathrm{~min} 95^{\circ} \mathrm{C}$, and 45 cycles at $15 \mathrm{~s} 95^{\circ} \mathrm{C}$ and $2 \mathrm{~min}$ $60^{\circ} \mathrm{C}$. FasL gene expression was calculated using the Sequence Detection System Vers. 1.7 from Applied Biosystems.

Alternatively, FasL and GAPDH expressions were also assessed by semi-quantitative conventional RT-PCR with the following cycle parameters: $94^{\circ} \mathrm{C} 1 \mathrm{~min}, 60^{\circ} \mathrm{C} 1 \mathrm{~min}$, 
$72^{\circ} \mathrm{C} 1 \mathrm{~min}, 37$ cycles for hFasL, and 28 cycles for GAPDH.

\section{Apoptosis assay}

H2009 cells were transfected as described above with vector control, Max or hFasL, and stimulated with medium control or PMA. After $24 \mathrm{~h}$ culture, all cells were harvested and stained with Annexin V-FITC to detect phosphatidylserine flip on apoptotic cells [24]. The percentage of apoptotic cells was analyzed by flow cytometry. Specificity of FasL-mediated apoptosis was confirmed by inhibition with soluble Fas-Fc fusion protein $(10 \mu \mathrm{g} / \mathrm{ml})[25,26]$.

\section{Western blotting}

For the detection of c-Myc and Max protein levels equal numbers of H2009 and Calu-6, and as controls Jurkat cells and peripheral blood mononuclear cells were lysed and protein samples were separated by electrophoresis. Specific levels of Max and c-Myc were detected by Western blotting using anti-c-Myc (clone 9E10) and anti-Max (clone H-2)

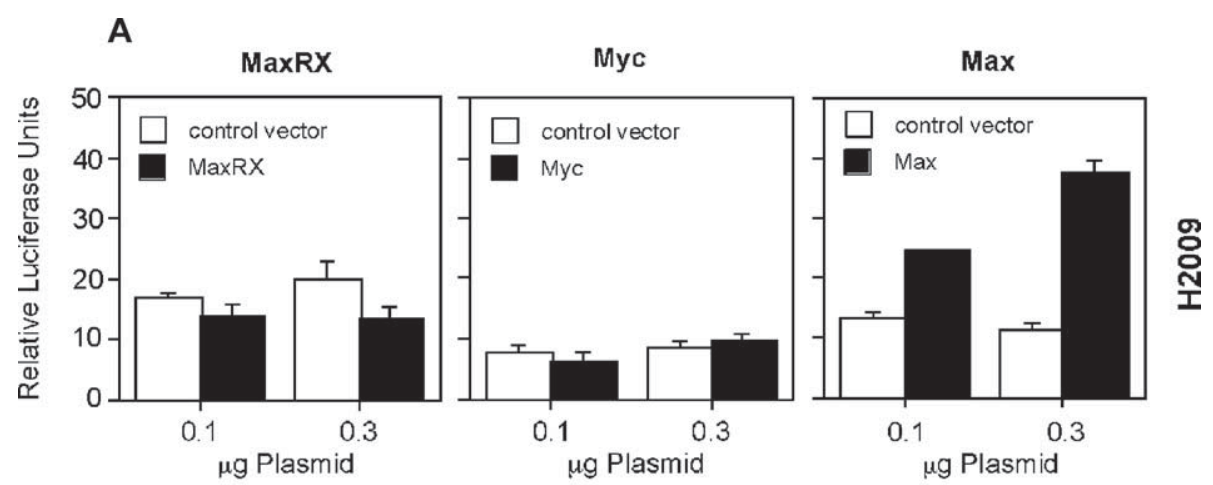

\section{B}


C

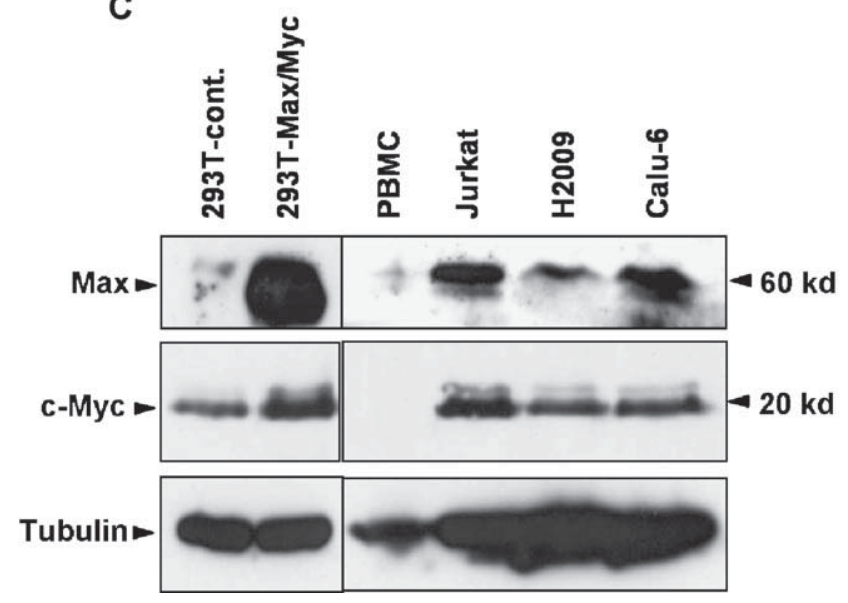

Fig. 1. Overexpression of Max induces FasL expression in H2009 and Calu-6 cells. H2009 (A) and Calu-6 (B) were co-transfected with 0.1 or $0.3 \mu$ g control vector (control vector), MaxRX, Myc, or Max expression vector, and the FasL promoter reporter construct. Luciferase activity, as a measurement of FasL promoter induction, was assessed in total cell lysates and normalized with $\beta$-galactosidase activity (relative luciferase units). Mean values \pm SD of a typical experiment out of three are shown. (C) Detection of Max and c-Myc protein levels by Western blot. Antibody specificity was tested by transfecting 293T cells with vector control, or c-Myc or Max expression vector. Peripheral blood mononuclear cells (PBMC) were used as negative control. Relative protein levels were compared to those in Jurkat cells, and with tubulin. 
antibodies (Santa Cruz, Labforce, Nunningen, Switzerland). The specificity of antibodies was tested with lysates from 293 T embryonic kidney fibroblasts transfected with control vector, c-Myc or Max. Equal protein loading was assessed by the detection of tubulin.

FasL protein levels were also detected by Western blotting. H2009 cells were transiently transfected with control vector, Max, and/or RelA and then stimulated for $18 \mathrm{~h}$ with $10 \mathrm{ng} / \mathrm{ml}$ PMA. Cell lysates were separated by electrophoresis and FasL protein levels were detected with an anti-FasL antibody (clone G247-4, BD Pharmingen, La Jolla, CA). Equal loading was confirmed by detection of tubulin.

\section{Results}

Basal FasL promoter activity in human non-small cell lung cancer cells is not c-Myc-responsive

Our previous studies on the regulation of the FasL promoter in $\mathrm{T}$ cells revealed that the c-Myc/Max heterodimer is required for activation-induced FasL promoter activity, and that the c-Myc/Max complex binds to a specific non-canonical DNA sequence in the FasL promoter $[9,12]$. Since c-Myc is overexpressed in many different tumors, including lung cancer, we aimed at analyzing the role of cMyc in FasL expression in the two different non-small cell lung cancer cell (NSCLC) lines H2009 and Calu-6. To assess whether inhibition of the c-Myc/Max complex or overexpression of c-Myc affects FasL expression, we employed a 1.2-kb human FasL promoter luciferase reporter construct, containing the above described c-Myc-binding site [12]. To our surprise, however, in both cell lines, basal FasL promoter activity was only minimally downregulated by MaxRX, a dominant-negative Max mutant, which dimerizes with Max and abrogates c-Myc/Max-dependent transcription $[9,27]$. Similarly, overexpression of c-Myc failed in most instances to enhance basal FasL promoter activity. In marked contrast, overexpression of Max resulted in a dosedependent distinct induction of FasL promoter activity in H2009 and Calu-6 (Figs. 1A and B). Thus, FasL expression in these NSCLC lines appears to be Max-responsive, and Max levels may represent a limiting factor for FasL expression.

We thus assessed the relative protein levels of c-Myc and Max in these cell lines. Fig. 1C shows that in particular H2009 cells, and to a lesser extent Calu-6 cells, express low levels of Max protein when compared to the lymphoma cell line Jurkat. In contrast, c-Myc was expressed at comparable levels in all cell lines. For comparison, non-dividing peripheral blood mononuclear cells showed very low expression of Max and c-Myc expression was absent. This supports the notion that Max expression may be limiting for c-Myc/Max-driven FasL transcription.
Max synergistically enhances phorbolester-and doxorubicin-induced FasL promoter activation

We next assessed whether overexpression of Max could enhance stimulation-induced FasL promoter activity in H2009 and Calu-6 cells. Previous reports have indicated that cellular stress or activation of the transcription factor NFkB can induce FasL expression in T cells, and tumor cells of both hematopoietic and non-hematopoietic origin $[21,28]$. We thus stimulated H2009 and Calu-6 cells with phorbolester (PMA), which activates protein kinase $\mathrm{C}$ and NFkB [29], or doxorubicin, which inhibits topoisomerase II, induces DNA damage, and therefore activates the Jun kinase pathway and NFkB [30]. Figs. 2A and B show that both cell lines responded to stimulation with PMA and doxorubicin with increased FasL promoter activity in a dose-dependent manner. Similarly, overexpression of Max alone was sufficient to induce a two-fold increase in FasL promoter activity, comparable to that observed with PMA or doxorubicin. Most intriguingly, however, combined overexpression of Max and stimulation with increasing concentrations of PMA or doxorubicin resulted in a pronounced synergistic promoter induction, strongly exceeding that observed by either stimulation or Max overexpression alone (Figs. 2A and B).

This synergistic induction of the FasL promoter was not only dependent on the concentrations of the agonistic
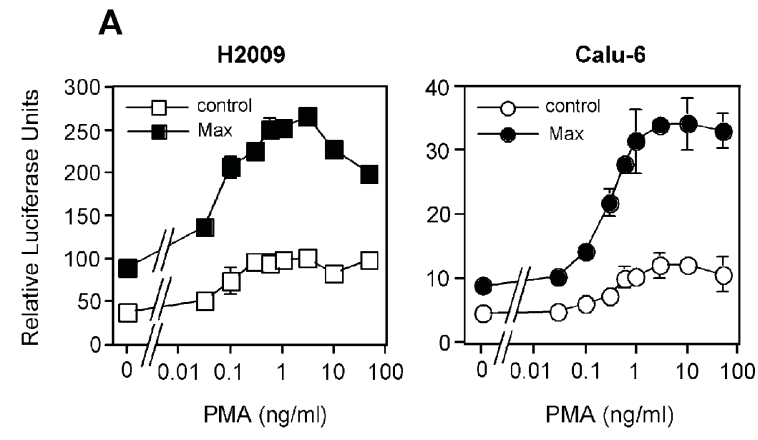

B


Fig. 2. Synergistic induction of the FasL promoter by Max and phorbolester or doxorubicin. H2009 ( $\square$, $\mathbf{\square})$ or Calu-6 $(\bigcirc, \boldsymbol{\bullet})$ cells were transiently transfected with $0.15 \mu \mathrm{g}$ vector control (control, $\square, \bigcirc)$ or $\operatorname{Max}(\mathbf{\square}, \bullet)$, and the FasL promoter reporter construct. Then cells were stimulated with increasing concentrations of PMA (A) or doxorubicin (B) for $16 \mathrm{~h}$. Mean values of relative luciferase activity \pm SD of a typical experiment out of three are shown. 
A

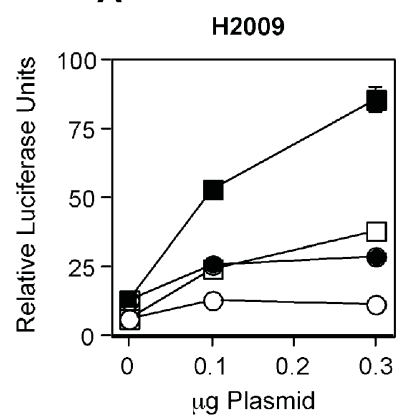

B



Calu-6

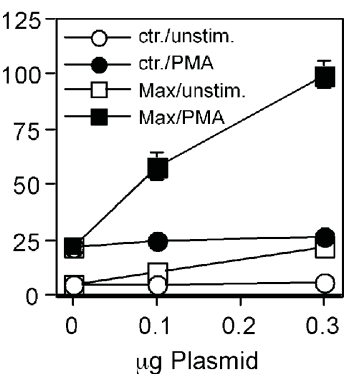

Calu-6

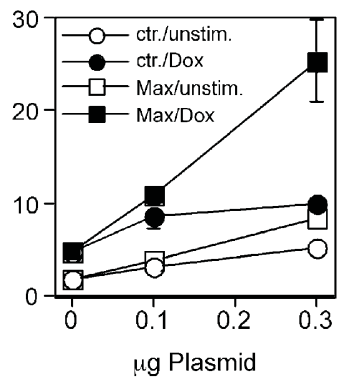

Fig. 3. Dose-dependency of Max expression on PMA- or doxorubicininduced FasL promoter activity. H2009 and Calu-6 cells were transiently transfected with various amounts of vector control (ctr., $\bigcirc, \bullet)$ or Max expression vector (Max, $\square, \boldsymbol{\square}$ ), and FasL promoter reporter construct. After stimulation with $10 \mathrm{ng} / \mathrm{ml}$ phorbolester (PMA, O, a) (A) or $1 \mu \mathrm{g} / \mathrm{ml}$ doxorubicin (Dox,, $\mathbf{\square}$ ) (B) for $16 \mathrm{~h}$ relative luciferase activity was assessed in cell lysates. Mean values \pm SD of a typical experiment out of three are shown.

triggers (PMA or doxorubicin), but also on the levels of Max. Transfection of H2009 or Calu-6 with increasing amounts of Max expression plasmid resulted in increased FasL promoter activity, which was further enhanced upon stimulation of cells with PMA (Fig. 3A) or doxorubicin (Fig. 3B). This synergistic induction of the FasL promoter was observed in both cell lines; however, in general, H2009 appeared to be more responsive to these FasL-inducing triggers, especially to doxorubicin (Figs. 2B and 3B).

\section{Synergistic induction of FasL promoter activity is mediated by Max and $N F \kappa B$}

Both phorbolester and DNA damage are known to induce the activation of $\mathrm{NF} \kappa \mathrm{B}[21,29,30]$. In addition, DNA damage and cellular stress also results in the activation of the transcription factor AP-1 (Jun/Fos) via the Jun kinase signaling pathway [21]. Both transcription factors, NFkB and AP-1, regulate FasL expression via distinct response elements in the FasL promoter and are responsible for the induction of FasL expression in T cells upon cellular stress [21,31]. We therefore investigated the respective roles of $\mathrm{NF} \kappa \mathrm{B}$ and the stress kinase pathway in FasL promoter induction in NSCLC lines. The activation of NFKB is efficiently blocked by the proteosome inhibitor lactacystin

A

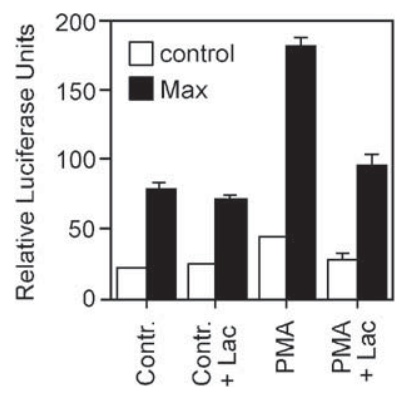

B

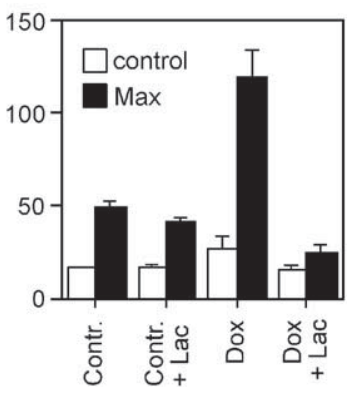

Fig. 4. Inhibition of PMA- or doxorubicin-induced FasL promoter activity by lactacystin. H2009 cells were transiently transfected with $0.15 \mu \mathrm{g}$ vector control (control, empty bars) or Max expression plasmid (Max, black bars), and the FasL promoter reporter construct. Cells were then pretreated with medium control or $5 \mu \mathrm{M}$ lactacystin (Lac) for $2 \mathrm{~h}$, before stimulation with medium control (contr.), $10 \mathrm{ng} / \mathrm{ml}$ phorbolester (PMA) (A), or $1 \mu \mathrm{g} / \mathrm{ml}$ doxorubicin (Dox) (B). Mean values \pm SD of a typical experiment out of two are shown.

[32]. We thus preincubated H2009 cells with lactacystin to inhibit NFKB activation and assessed FasL promoter induction in response to Max overexpression and stimulation with PMA or doxorubicin. As can be seen from Figs. 4A and B, lactacystin had only a minimal effect on the Max-induced increase of FasL promoter activity, however, it strongly reduced PMA- (Fig. 4A) and doxorubicin-induced (Fig. 4B) promoter activity in control cells and Max-overexpressing cells.
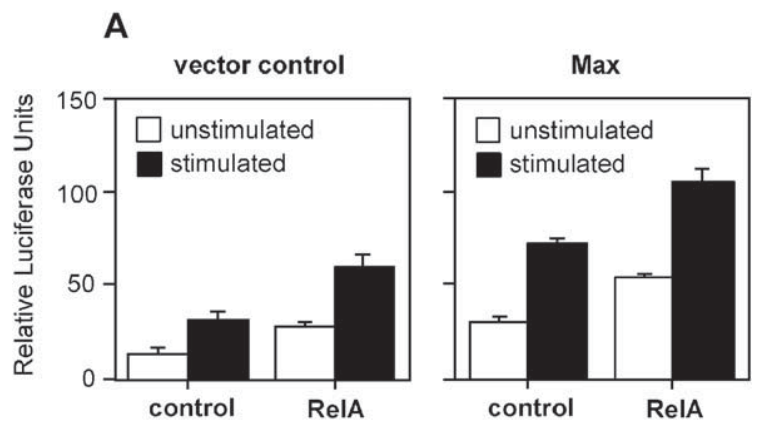

B


Fig. 5. Induction of FasL promoter activity by RelA, but not MEKK1. H2009 cells were transiently co-transfected with vector control or Max $(0.15 \mu \mathrm{g})$, and RelA $(0.15 \mu \mathrm{g})(\mathrm{A})$, or MEKK1 $(0.15 \mu \mathrm{g})(\mathrm{B})$. Cells were then stimulated with medium control (control, empty bars) or $5 \mathrm{ng} / \mathrm{ml}$ PMA (stimulated, black bars) for $16 \mathrm{~h}$. Mean values \pm SD of relative luciferase activities of a typical experiment out of two are shown. 
Since inhibitors may often have unspecific effects, we further investigated the role of $\mathrm{NF} \kappa \mathrm{B}$ in FasL regulation by overexpressing RelA, the p65 subunit of the NFKB complex [21,33]. Overexpression of RelA in H2009 cells alone was sufficient to induce an increase in FasL promoter activity, which however, was further synergistically increased by coexpression of Max and stimulation with PMA (Fig. 5A).

To investigate the role of the stress kinase pathway in FasL induction in H2009 cells, we also co-transfected cells with MEKK1, a MAP kinase kinase kinase, which induces the activation of the Jun kinase and therefore of AP-1 [21,28,34,35]. To our surprise, we failed to detect an increase in spontaneous, PMA- or Max-induced FasL promoter activity, but rather observed a strong inhibition (Fig. 5B). Thus, these data support a synergistic control of the FasL promoter



\section{Regulation of the endogenous FasL expression by Max and $N F \kappa B$}

Gene promoter reporter assays are commonly used to study the regulation of a given gene. In particular, the FasL promoter construct used in this study has been proven useful for the characterization of many different signal transduction pathways and transcription factors leading to FasL induction [9,12,21,28]. However, promoter reporter constructs may only partially reflect the regulation of the endogenous promoter and FasL gene expression. We therefore further assessed whether Max and PMA may also synergistically induce endogenous FasL expression in H2009 lung cancer cells. H2009 cells were transiently transfected with control plasmid or Max expression plasmid, and stimulated with buffer control of PMA. After $10 \mathrm{~h}$, total RNA was isolated and FasL expression was assessed by RT-PCR. As is shown in Fig. 6A, FasL expression was readily detected in FasLtransfected cells (positive control). Minimal FasL transcription was observed in control- or Max-transfected cells, and only low levels were detected upon stimulation by PMA.
Combined overexpression of Max and stimulation with PMA, however, synergistically induced endogenous FasL expression. Identical results were obtained by using quantitative real-time RT-PCR (Fig. 6B). These findings were also confirmed by the detection of FasL protein (Fig. 6C). Co-transfection of Max and RelA resulted in increased FasL protein levels upon stimulation with PMA, whereas either Max or RelA transfection, or PMA stimulation alone resulted only in low FasL expression.

Thus, these experiments analyzing endogenous FasL expression support the above described results, using the FasL promoter reporter construct, and indicate an important role for Max and NFkB in the regulation of FasL expression in human NSCLC lines.

\section{Discussion}

Initially characterized as a cytotoxic effector mechanism in $\mathrm{T}$ cells, recent years have described an enormous variety of different FasL-mediated effects in various physiological and pathological situations (reviewed in Refs. [36-38]. Similarly, FasL appears not to be restricted to the lymphoid cell lineage, but shows a broad expression pattern in hematopoietic and non-hematopoietic cells (reviewed in Ref. [13]). In particular, FasL expression in tumor cells has received considerable attention due to its suggested implication in immune escape (reviewed in Ref. [15]). Tumor cell-expressed FasL has been thought to induce apoptosis in tumor-infiltrating cytotoxic $\mathrm{T}$ cells and may therefore save tumor cells from destruction by the immune system. While many studies have supported this idea $[14,16,17,39,40]$, others have reported opposing findings $[41,42]$. This controversial issue has not been solved so far and the expression and the biological function of FasL in tumors probably depend on the context and cellular environment (reviewed in Ref. [43]). For example, FasL-transfected tumor cells were found to cause a strong
A

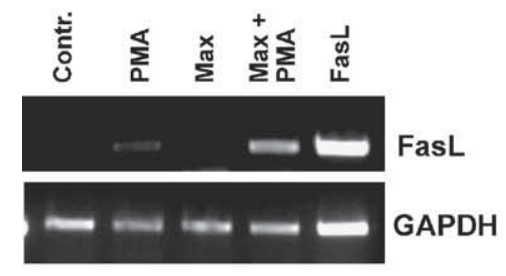

B



C

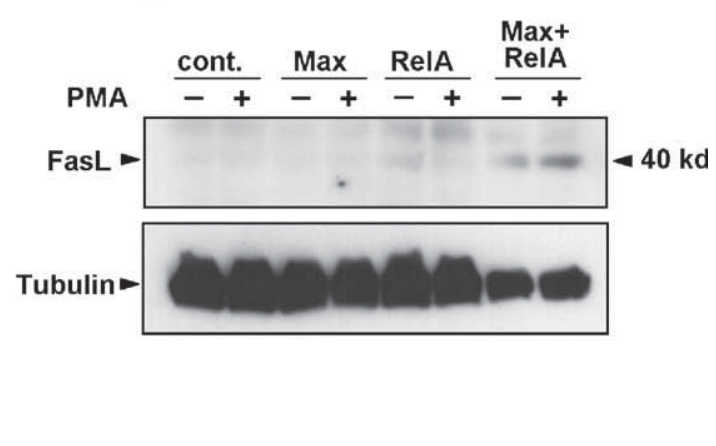

Fig. 6. Synergistic induction of endogenous FasL expression by Max and PMA. H2009 cells were transfected with vector control, Max, or hFasL as positive control, and stimulated with medium control or $10 \mathrm{ng} / \mathrm{ml} \mathrm{PMA.} \mathrm{After} 10 \mathrm{~h}$, total RNA was isolated and FasL induction was assessed by RT-PCR (A). Equal loading was controlled by amplification of the house-keeping gene GAPDH. Samples of the same experiment were also analyzed by quantitative real-time PCR (B). A typical experiment out of three is shown. (C) FasL protein levels in Max- and/or RelA-transfected H2009 cells, either left unstimulated or stimulated with $10 \mathrm{ng} / \mathrm{ml}$ PMA, were detected by Western blot. Equal loading was controlled by detection of tubulin. 
inflammatory response and neutrophil-mediated tumor destruction [41]. However, if transforming growth factor (TGF) $\beta$, often overexpressed in a variety of tumors, was co-expressed, infiltrating leukocytes were killed by the tumor-expressed FasL and no inflammation was induced [40].

Regardless of the suggested biological effects of FasL in tumor cells, comparably little is known about the regulation of this molecule in non-lymphoid cells and in particular in tumor cells. We have previously shown that in T cells FasL is critically regulated by the transcription factor c-Myc/Max [9-12]. c-Myc plays a crucial role in cell cycle progression and is expressed in proliferating cells, including activated $\mathrm{T}$ cells and tumor cells. Thus, we have suggested that c-Myc might ensure that FasL is only efficiently expressed in cycling $\mathrm{T}$ effector cells upon restimulation, therefore preventing uncontrolled tissue damage [9]. c-Myc is frequently overexpressed in various tumor cells and possibly contributes to the uncontrolled proliferation of many tumors. Particularly in lung cancer cells, gene duplication of c$m y c$, as detected by FISH (fluorescence in situ hybridization), has been reported [44]. We thus aimed at characterizing the role of c-Myc in FasL expression in human lung cancer cell lines. Our results indicate an important role for the c-Myc/Max transcription factor in tumor FasL expression. Interestingly, however, we observed that neither inhibition of Max nor overexpression of c-Myc was effective in modifying basal FasL expression in two different NSCLC lines. In contrast, we found that only overexpression of Max caused a significant increase in FasL expression. We thus suggest that Max, rather than c-Myc, represents a limiting factor in the regulation of FasL transcription in these lung cancer cell lines. Using Western blotting, we detected abundant levels of c-Myc in H2009 and Calu-6, comparable to those found in the leukemic T cell line Jurkat (Fig. 1C). While c-Myc expression is cell cycle stage-dependent, Max expression has been reported to be constitutive [45]. However, it has been shown that c-Myc expression in tumor cells might be deregulated and abundant, and possibly Max protein might not be available at an optimal ratio to promote gene expression, for example, fas $L$. In agreement with this notion, we have found relatively low protein levels of Max in Calu-6 and in particular in H2009 cells, when compared to Jurkat cells (Fig. 1C). Alternatively, overexpression of Max might lead to the formation of Max homodimers, which may regulate gene transcription independently of cMyc [46,47]. It is interesting to note that overexpression of Max in vitro and in vivo causes opposing effects on cellular proliferation and differentiation than $\mathrm{c}-\mathrm{Myc}$, and even antagonizes the oncogenic activity of Myc $[48,49]$.

As in T cells, we have found that c-Myc/Max alone is not sufficient to induce potent FasL expression in lung cancer cells. While $\mathrm{T}$ cell receptor-induced FasL expression in $\mathrm{T}$ cells depends on activation-induced transcription factors, such as NFAT, NFKB, and Egr-1 and -3 (reviewed in Ref. [31]), in lung cancer cells, c-Myc/Max appears to synergize particularly well with signals that activate NFkB. Both, PMA- and doxorubicin-induced FasL expressions were efficiently blocked by lactacystin, a potent inhibitor of the

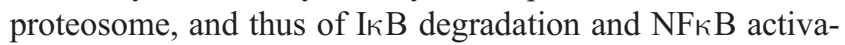
tion. In addition, overexpression of the NFkB subunit RelA further enhanced Max-induced FasL expression. This strongly supports a cooperative role for NFkB and c-Myc/ Max in the regulation of FasL expression in lung cancer cells.

In this study, we were not only able to show the synergistic role of $\mathrm{c}-\mathrm{Myc} / \mathrm{Max}$ and $\mathrm{NF} \kappa \mathrm{B}$ in the induction of a FasL promoter reporter construct, transiently transfected into two different lung cancer cell lines, but also to demonstrate the synergistic induction of endogenous fasL gene. Using conventional and real-time RT-PCR, we observed a considerably higher induction of FasL expression upon stimulation of the cells with Max and PMA than either trigger was able to induce alone. This tumor-expressed FasL appeared to be biologically active since we observed increased apoptosis induction in Max-transfected and PMAstimulated H2009 cells (which was blocked by soluble Fas fusion protein [25]) than in cells stimulated with PMA only (data not shown). Thus, in $\mathrm{H} 2009$ simultaneous NFkB activation and Max overexpression may cause FasL-mediated cell death. This notion is also supported by the fact that Max- and RelA-transfected H2009 cells have increased FasL protein expression but lower tubulin expression, reflecting a lower recovery of cells, most likely due to Fas/FasL-dependent cell death.

Doxorubicin not only induces the activation of $\mathrm{NF} \kappa \mathrm{B}$, but also Jun kinase and thus AP-1. Different reports have demonstrated an important role for both transcription factor in stress- and DNA damage-induced FasL expression in leukemic T cells $[21,28,35,50]$. It was thus surprising for us that overexpression of the MAP kinase kinase kinase MEKK1 in $\mathrm{H} 2009$ cells did not result in increased promoter induction, but rather in an inhibition of Max- and PMAinduced FasL expressions. Although MEKK1 can activate other MAP kinases, such as ERK-1 and -2, it has been reported to predominately activate Jun kinase and therefore AP-1 [34,51]. Thus, AP-1 may possibly represent a rather negative regulatory element in FasL expression in H2009 cells, however, whether this is a general mechanism in FasL regulation in various tumor cells remains to be investigated.

In conclusion, our results show an important role for Max and $\mathrm{NF} \kappa \mathrm{B}$ in the regulation of FasL expression in human NSCLC lines, which might contribute to the previously observed FasL overexpression in various lung cancers [14].

\section{Acknowledgments}

The authors would like to thank Igor Cima and Christine Murtin for technical and intellectual support, Doug Green for critical advice, Robert Eisenman, Bruno Amati, and Michael Karin for kindly providing expression plasmids, 
and Jean-Marc Zingg for the use of the luminometer. This study was supported by grants from the Swiss National Science Foundation, Oncosuisse, Bernese Cancer League and EU Cost Action 844 to T.B.

\section{References}

[1] B. Amati, K. Alevizopoulos, J. Vlach, Myc and the cell cycle, Front. Biosci. 3 (1998) D250-D268.

[2] E.V. Schmidt, The role of c-myc in cellular growth control, Oncogene 18 (1999) 2988-2996.

[3] L.M. Boxer, C.V. Dang, Translocations involving c-myc and c-myc function, Oncogene 20 (2001) 5595-5610.

[4] L.M. Facchini, L.Z. Penn, The molecular role of Myc in growth and transformation: recent discoveries lead to new insights, FASEB J. 12 (1998) 633-651.

[5] A.C. Davis, M. Wims, G.D. Spotts, S.R. Hann, A. Bradley, A null cmyc mutation causes lethality before 10.5 days of gestation in homozygotes and reduced fertility in heterozygous female mice, Genes Dev. 7 (1993) 671-682.

[6] G.I. Evan, A.H. Wyllie, C.S. Gilbert, T.D. Littlewood, H. Land, M. Brooks, C.M. Waters, L.Z. Penn, D.C. Hancock, Induction of apoptosis in fibroblasts by c-myc protein, Cell 69 (1992) 119-128.

[7] S. Pelengaris, M. Kahn, G. Evan, Suppression of Myc-induced apoptosis in beta cells exposes multiple oncogenic properties of Myc and triggers carcinogenic progression, Cell 109 (2002) 321-334

[8] A.O. Hueber, M. Zornig, D. Lyon, T. Suda, S. Nagata, G.I. Evan, Requirement for the CD95 receptor-ligand pathway in c-Myc-induced apoptosis, Science 278 (1997) 1305-1309.

[9] T. Brunner, S. Kasibhatla, M.J. Pinkoski, C. Frutschi, N.J. Yoo, F. Echeverri, A. Mahboubi, D.R. Green, Expression of Fas ligand in activated T cells is regulated by c-Myc, J. Biol. Chem. 275 (2000) 9767-9772.

[10] R. Wang, T. Brunner, L. Zhang, Y. Shi, Fungal metabolite FR901228 inhibits c-Myc and Fas ligand expression, Oncogene 17 (1998) $1503-1508$.

[11] L. Genestier, S. Kasibhatla, T. Brunner, D.R. Green, Transforming growth factor betal inhibits fas ligand expression and subsequent activation-induced cell death in $\mathrm{T}$ cells via downregulation of cMyc [In Process Citation], J. Exp. Med. 189 (1999) 231-239.

[12] S. Kasibhatla, H.M. Beere, T. Brunner, F. Echeverri, D.R. Green, A 'non-canonical' DNA-binding element mediates the response of the fas-ligand promoter to c-Myc, Curr. Biol. 10 (2000) 1205-1208.

[13] P.R. Walker, P. Saas, P.Y. Dietrich, Tumor expression of Fas ligand (CD95L) and the consequences, Curr. Opin. Immunol. 10 (1998) $564-572$.

[14] G.A. Niehans, T. Brunner, S.P. Frizelle, J.C. Liston, C.T. Salerno, D.J. Knapp, D.R. Green, R.A. Kratzke, Human lung carcinomas express Fas ligand, Cancer Res. 57 (1997) 1007-1012.

[15] J. O'Connell, M.W. Bennett, G.C. O’Sullivan, J.K. Collins, F. Shanahan, The Fas counterattack: cancer as a site of immune privilege, Immunol. Today 20 (1999) 46-52.

[16] M. Hahne, D. Rimoldi, M. Schroter, P. Romero, M. Schreier, L.E. French, P. Schneider, T. Bornand, A. Fontana, D. Lienard, J. Cerottini, J. Tschopp, Melanoma cell expression of Fas (Apo-1/CD95) ligand: implications for tumor immune escape, Science 274 (1996) $1363-1366$.

[17] D. Cefai, R. Schwaninger, M. Balli, T. Brunner, C.D. Gimmi, Functional characterization of Fas ligand on tumor cells escaping active specific immunotherapy, Cell Death Differ. 8 (2001) 687-695.

[18] J.L. Broers, J. Viallet, S.M. Jensen, H. Pass, W.D. Travis, J.D. Minna, R.I. Linnoila, Expression of c-myc in progenitor cells of the bronchopulmonary epithelium and in a large number of non-small cell lung cancers, Am. J. Respir. Cell Mol. Biol. 9 (1993) 33-43.
[19] H.A. Ozkara, S. Ozkara, S. Topcu, W.E. Criss, Amplification of the c-myc oncogene in non-small cell lung cancer, Tumori 85 (1999) $508-511$.

[20] B.E. Johnson, J.F. Brennan, D.C. Ihde, A.F. Gazdar, Myc family DNA amplification in tumors and tumor cell lines from patients with smallcell lung cancer, J. Natl. Cancer Inst. Monographs, (1992) 39-43.

[21] S. Kasibhatla, T. Brunner, L. Genestier, F. Echeverri, A. Mahboubi, D.R. Green, DNA damaging agents induce expression of Fas ligand and subsequent apoptosis in T lymphocytes via the activation of NFkappa B and AP-1, Mol. Cell 1 (1998) 543-551.

[22] J.K. Westwick, C. Weitzel, A. Minden, M. Karin, D.A. Brenner, Tumor necrosis factor alpha stimulates AP-1 activity through prolonged activation of the c-Jun kinase, J. Biol. Chem. 269 (1994) 26396-26401.

[23] V. Baud, Z.G. Liu, B. Bennett, N. Suzuki, Y. Xia, M. Karin, Signaling by proinflammatory cytokines: oligomerization of TRAF2 and TRAF6 is sufficient for JNK and IKK activation and target gene induction via an amino terminal effector domain, Genes Dev. 13 (1999) $1297-1308$.

[24] S.J. Martin, C.P. Reutelingsperger, A.J. McGahon, J.A. Rader, R.C. van Schie, D.M. LaFace, D.R. Green, Early redistribution of plasma membrane phosphatidylserine is a general feature of apoptosis regardless of the initiating stimulus: inhibition by overexpression of Bcl-2 and Abl, J. Exp. Med. 182 (1995) 1545-1556.

[25] T. Brunner, R.J. Mogil, D. La Face, N.J. Yoo, A. Mahboubi, F. Echeverri, S.J. Martin, W.R. Force, D.H. Lynch, C.F. Ware, et al., Cell-autonomous Fas (CD95)/Fas-ligand interaction mediates activation-induced apoptosis in T-cell hybridomas, Nature 373 (1995) 441-444.

[26] T. Brunner, N.J. Yoo, D. La Face, C.F. Ware, D.R. Green, Activationinduced cell death in murine $\mathrm{T}$ cell hybridomas. Differential regulation of Fas (CD95) versus Fas ligand expression by cyclosporin A and FK506, Int. Immunol. 8 (1996) 1017-1026.

[27] B. Amati, M.W. Brooks, N. Levy, T.D. Littlewood, G.I. Evan, H. Land, Oncogenic activity of the c-Myc protein requires dimerization with Max, Cell 72 (1993) 233-245.

[28] F.G. Harwood, S. Kasibhatla, I. Petak, R. Vernes, D.R. Green, J.A. Houghton, Regulation of FasL by NF-kappaB and AP-1 in Fas-dependent thymineless death of human colon carcinoma cells, J. Biol. Chem. 275 (2000) 10023-10029.

[29] N.M. Steffan, G.D. Bren, B. Frantz, M.J. Tocci, E.A. O’Neill, C.V. Paya, Regulation of IkB alpha phosphorylation by PKC- and $\mathrm{Ca}(2+)-$ dependent signal transduction pathways, J. Immunol. 155 (1995) $4685-4691$.

[30] I. Lavon, E. Pikarsky, E. Gutkovich, I. Goldberg, J. Bar, M. Oren, Y. Ben-Neriah, Nuclear factor-kappaB protects the liver against genotoxic stress and functions independently of p53, Cancer Res. 63 (2003) 25-30.

[31] M.M. Kavurma, L.M. Khachigian, Signaling and transcriptional control of Fas ligand gene expression, Cell Death Differ. 10 (2003) 36-44.

[32] M.B. Grisham, V.J. Palombella, P.J. Elliott, E.M. Conner, S. Brand, H.L. Wong, C. Pien, L.M. Mazzola, A. Destree, L. Parent, J. Adams, Inhibition of NF-kappa B activation in vitro and in vivo: role of $26 \mathrm{~S}$ proteasome, Methods Enzymol. 300 (1999) 345-363.

[33] S. Kasibhatla, L. Genestier, D.R. Green, Regulation of fas-ligand expression during activation-induced cell death in $\mathrm{T}$ lymphocytes via nuclear factor kappaB, J. Biol. Chem. 274 (1999) 987-992.

[34] Y. Xia, C. Makris, B. Su, E. Li, J. Yang, G.R. Nemerow, M. Karin, MEK kinase 1 is critically required for c-Jun N-terminal kinase activation by proinflammatory stimuli and growth factor-induced cell migration, Proc. Natl. Acad. Sci. U. S. A. 97 (2000) 5243-5248.

[35] M. Faris, N. Kokot, K. Latinis, S. Kasibhatla, D.R. Green, G.A. Koretzky, A. Nel, The c-Jun N-terminal kinase cascade plays a role in stress-induced apoptosis in Jurkat cells by up-regulating Fas ligand expression, J. Immunol. 160 (1998) 134-144.

[36] M.J. Pinkoski, D.R. Green, Fas ligand, death gene, Cell Death Differ. 6 (1999) 1174-1181. 
[37] M.J. Pinkoski, T. Brunner, D.R. Green, T. Lin, Fas and Fas ligand in gut and liver, Am. J. Physiol.: Gasterointest. Liver Physiol. 278 (2000) G354-G366.

[38] T. Brunner, C. Wasem, R. Torgler, I. Cima, S. Jakob, N. Corazza, Fas (CD95/Apo-1) ligand regulation in $\mathrm{T}$ cell homeostasis, cell-mediated cytotoxicity and immune pathology, Semin. Immunol. 15 (2003) $167-176$.

[39] M.W. Bennett, J. O'Connell, G.C. O’Sullivan, C. Brady, D. Roche, J.K. Collins, F. Shanahan, The Fas counterattack in vivo: apoptotic depletion of tumor-infiltrating lymphocytes associated with Fas ligand expression by human esophageal carcinoma, J. Immunol. 160 (1998) $5669-5675$.

[40] J.J. Chen, Y. Sun, G.J. Nabel, Regulation of the proinflammatory effects of Fas ligand (CD95L), Science 282 (1998) 1714-1717.

[41] K. Seino, N. Kayagaki, K. Okumura, H. Yagita, Antitumor effect of locally produced CD95 ligand, Nat. Med. 3 (1997) 165-170.

[42] N.P. Restifo, Not so Fas: re-evaluating the mechanisms of immune privilege and tumor escape, Nat. Med. 6 (2000) 493-495.

[43] J. O'Connell, A. Houston, M.W. Bennett, G.C. O'Sullivan, F. Shanahan, Immune privilege or inflammation? Insights into the Fas ligand enigma, Nat. Med. 7 (2001) 271-274.

[44] M. Gugger, E. Burckhardt, A. Kappeler, H. Hirsiger, J.A. Laissue, L. Mazzucchelli, Quantitative expansion of structural genomic alterations in the spectrum of neuroendocrine lung carcinomas, J. Pathol. 196 (2002) 408-415.
[45] C. Grandori, S.M. Cowley, L.P. James, R.N. Eisenman, The Myc/ Max/Mad network and the transcriptional control of cell behavior, Annu. Rev. Cell Dev. Biol. 16 (2000) 653-699.

[46] T.A. Baudino, J.L. Cleveland, The Max network gone mad, Mol. Cell. Biol. 21 (2001) 691-702.

[47] P.J. Hurlin, E. Steingrimsson, N.G. Copeland, N.A. Jenkins, R.N. Eisenman, Mga, a dual-specificity transcription factor that interacts with Max and contains a T-domain DNA-binding motif, EMBO J. 18 (1999) 7019-7028.

[48] M. Canelles, M.D. Delgado, K.M. Hyland, A. Lerga, C. Richard, C.V. Dang, J. Leon, Max and inhibitory c-Myc mutants induce erythroid differentiation and resistance to apoptosis in human myeloid leukemia cells, Oncogene 14 (1997) 1315-1327.

[49] G.J. Lindeman, A.W. Harris, M.L. Bath, R.N. Eisenman, J.M. Adams, Overexpressed max is not oncogenic and attenuates myc-induced lymphoproliferation and lymphomagenesis in transgenic mice, Oncogene 10 (1995) 1013-1017.

[50] C. Friesen, I. Herr, P.H. Krammer, K.-M. Debatin, Involvement of the CD95 (APO-1/Fas) receptor/ligand system in drug-induced apoptosis in leukemia cells, Nat. Med. 2 (1996) 574-577.

[51] H. Vuong, T. Patterson, P. Shapiro, D.V. Kalvakolanu, R. Wu, W.Y. Ma, Z. Dong, S.R. Kleeberger, S.P. Reddy, Phorbol ester-induced expression of airway squamous cell differentiation marker, SPRR1B, is regulated by protein kinase Cdelta/Ras/MEKK1/MKK1-dependent/AP-1 signal transduction pathway, J. Biol. Chem. 275 (2000) 32250-32259. 